Tusa, N., J.W. Grosser, and F.G. Gmitter, Jr. 1990. Plant regeneration of 'Valencia' sweet orange, 'Femminello' lemon, and the interspecific somatic hybrid following protoplast fusion. J. Amer. Soc. Hort. Sci. 115:10431046.

Vardi, A., P. Arzee-Gonen, A. Frydman-Shani, and S. Bleichman. 1989. Protoplast fusion mediated transfer of organelles from Microcitrus and Citrus and regeneration of novel alloplasmic trees. Theor. Applied Genet. 78:741-747.
Vardi, A., A. Breiman, and E. Galun. 1987. Citrus cybrids: Production by donor-recipient protoplast-fusion and verification by mitochondrial-DNA restriction profiles. Theor. Applied Genet. 75:51-58.

Vardi, A. and E. Galun. 1988. Recent advances in protoplast culture of horticultural crops: Citrus. Scientia Hort. 37:217-230.

Vardi, A., P. Spiegel-Roy, and E. Galun. 1982. Plant regeneration from Citrus protoplasts: Variability in methodological requirements among cultivars and species. Theor. Applied Genet. 62:171-176.

\title{
A Review of Plant Embryo Culture
}

\author{
Mark P. Bridgen \\ Department of Plant Science, U-67, 1376 Storrs Road, University of Connecticut, Storrs, CT 06269
}

Tapping germplasm resources to improve cultivated plants depends on introducing natural variability through traditional and biotechnological breeding methods. Intervarietal and interspecific crosses, followed by selection, have accounted for the improvement in quality and yield potential of practically all major crops (Raghavan, 1986). One biotechnological technique that has been beneficial is embryo culture.

Embryo culture involves isolating and growing an immature or mature zygotic embryo under sterile conditions on an aseptic nutrient medium with the goal of obtaining a viable plant. The basic premise for this technique is that the integrity of the hybrid genome is retained in a developmentally arrested or an abortive embryo and that its potential to resume normal growth may be realized if supplied with the proper growth substances. The technique depends on isolating the embryo without injury, formulating a suitable nutrient medium, and inducing continued embryogenic growth and seedling formation.

The culture of immature embryos is used to rescue embryos that would normally abort or that would not undergo the progressive sequence of ontogeny. This process is difficult due to the tedious dissection necessary and the complex nutrient medium requirements. Success with this type of culture depends strongly on the developmental stage of the embryo when it is isolated (Monnier, 1978; Raghavan, 1980).

The culture of mature embryos from ripened seeds is used to eliminate seed germination inhibitors or to shorten the breeding cycle if, for example, dormancy is a problem. This culture is easy and only requires a simple nutrient medium with agar, sugar, and minerals.

\section{HISTORY}

Embryo culture, sometimes called embryo rescue, is an in vitro technique that has been used for more than half a century to save the hybrid products of fertilization when they might otherwise degenerate. Success was first achieved in 1904 by Hannig who obtained viable plants from mature embryos of two crucifers that were isolated aseptically and grown on a mineral salt medium supplemented with sugar (Norstog, 1979). In 1924, Dietrich cultured mature and immature embryos of various plant species to determine whether they could still germinate without completing the dormancy period. He reported that the mature embryos grew immediately, circumventing dormancy. The immature embryos germinated precociously without further embryo development. Laibach first described zygotic embryo culture for interspecific hybridization in 1925 . He observed that seeds from interspecific crosses between Linum perenne L. x Linum austriacum L. were nonviable; however, if embryos were excised early during seed development and cultured in vitro, then embryo abortion was overcome. Later, van Overbeek et al. (1941) discovered that small Datura hybrid embryos could be grown in culture on media containing

Storrs Agricultural Experiment Station no. 1503. The cost of publishing this paper was defrayed in part by the payment of page charges. Under postal regulations, this paper therefore must be hereby marked advertisement solely to indicate this fact. coconut milk. This discovery ultimately led to understanding the importance of reduced $\mathrm{N}$ in the form of amino acids for embryo culture.

Since the early 1940s, embryo culture has been used increasingly to understand the physical and nutritional requirements for embryonic development, bypass seed dormancy, shorten the breeding cycle, test seed viability, provide material for micropropagation, and rescue immature hybrid embryos from incompatible crosses (Hu and Wang, 1986).

\section{APPLICATIONS}

Embryo culture is one of the earliest forms of in vitro culture applied to practical problems and is probably the tissue culture technique that has proven of greatest value to breeders (Dunwell, 1986). Its major application in plant breeding has been for interspecific hybridization.

Many unsuccessful crosses result from embryo abortion. Early embryo abortion occurs primarily because the endosperm fails to develop properly (Hu and Wang, 1986). With interspecific crosses, intergeneric crosses, and crosses between diploids and tetraploids, the endosperm often develops poorly or not at all. By aseptically culturing the embryo in a nutrient medium, this problem may be overcome. Embryos of some nonviable hybrids may possess the potential for initiating development by avoiding postzygotic barriers within the mother plant. Several successful cases have been documented with embryos arising from interspecific hybrids and intergeneric hybrids (Ramming, 1990; Sharma and Gill, 1983; Williams, 1980; Williams and De Lautour, 1980; Williams et al., 1982).

Embryo culture can shorten the breeding cycle by overcoming dormancy in seeds. Dormancy may be caused by endogenous inhibitors, light requirements, low temperatures, dry storage requirements, and embryo immaturity (Yeung et al., 1981). Seed dormancy factors may be localized in the seedcoat, the endosperm, or both. By removing the embryos from the influences of these factors, the embryos germinate and grow quickly and the breeding cycle is shortened. Isolated embryos can also be vernalized and may, in some instances, reduce the generation time by 40 days (Sharma and Gill, 1983).

In addition to the applied uses of embryo culture, the procedure is useful in basic studies. Growing embryos outside the ovule (ex ovulo) is an excellent way to study the nutrition and metabolism of the embryos at various stages of development. The technique can also be used to examine the growth requirements of embryos, the effects of phytohormones and environmental conditions on zygotic embryogenesis, and the regeneration potentials of whole embryos and their segments (Yeung et al., 1981). Embryo culture can be used to localize sites of germination promoters and inhibitors, for studies of embryogenesis, and for cryopreservation (Grout, 1986).

Embryo culture can be used to produce haploids through eliminating chromosomes following distant hybridization. This can occur by rescuing haploid maternal embryos in which the paternal chromosomes have been eliminated. In these situations, fertilization occurs, but the pollen parent chromosomes are subsequently eliminated by the 
seed parent. The viability of the haploid embryo can only be achieved through embryo culture. Chromosome doubling of the rescued embryo produces a homozygote monoploid.

Embryo culture can be used to propagate plants vegetatively. Embryos from genera that have both juvenile and adult characteristics are used as starting material for vegetative propagation. Embryos are responsive because they are juvenile. With the Poaceae, organogenesis occurs easily from juvenile callus tissue. Conifer propagation via immature calli derived from young embryos and axillary shoot formation is also easy. A major problem with this technique, however, is that clones are not produced from the zygotic material unless the embryos have developed from nucellar tissue, as in many types of Citrus.

Embryo culture can be used to study precocious germination, the germination of embryos before the completion of normal embryo development. Usually, precocious germination causes the formation of weak seedlings. To understand the factors that regulate the orderly development of embryos in nature, embryos can be cultured under various conditions to determine what simulates embryological development. Precocious germination occurs because inhibitors are lost when the testa is removed or because the negative osmotic potential is a higher value in vivo. Precocious germination has been prevented in Prunus through ovule culture, where the integument acts as a natural inhibitor (Ramming, 1985).

Embryo culture has been very useful in determining seed viability. This use arose out of early findings that there was a good correlation between the growth of excised embryos of non-after-ripened peach [Prunus persica (L.) Batsch.] seeds and germination of the afterripened seeds (Tukey, 1944). Embryo culture allows the rapid testing of seed viability when seed dormancy can be circumvented.

\section{TECHNIQUES}

In most situations, embryos are located in the sterile environment of the ovule and surface sterilization of embryos is not necessary. Instead, entire ovules or ovaries are surface-sterilized and then embryos are removed aseptically from the surrounding tissues. Since the embryo is often well-protected by surrounding tissues, harsh procedures may be used in surface disinfection. Thus, axenic cultures of embryos are often easily established. Direct disinfection of embryos is needed if seedcoats are cracked or if endophytic pathogens exist inside the seedcoats, as with fescue (Festuca spp.L.), corn (Zea mays L.), and dogwood (Cornus spp. L.) seeds.

The dissection of the embryos can produce problems. Large embryos are not difficult to excise. However, small embryos require the use of microdissecting tools and a dissecting microscope to excise without injury. Embryos are easily damaged when the seedcoat is cut; it is also important that the excised embryo does not become desiccated during culture (Rangan, 1984).

The process of excising immature embryos varies with species. However, many times an incision can be made at the micropylar end of the young ovule and pressure applied at the opposite end to force the embryo out through the opening. If liquid endosperm surrounds the embryo, the pressure it exerts may injure the fragile embryonic tissue if caution is not exercised. When heart-stage and younger embryos are excised, it is important to keep the suspensors intact (Hu and Wang, 1986).

\section{REQUIREMENTS FOR SUCCESS}

Successful development of an embryo depends on many factors. As with most other processes, the plant genotype greatly influences success. Embryos of some species are easier to grow in culture than are others, and differences sometimes occur between closely related cultivars (Collins and Grosser, 1984; Rangan, 1984).

As already indicated, small embryos are difficult to grow in vitro. Specialized techniques can be used to improve success. The use of "nurse" endosperm involves inserting a hybrid embryo into an endosperm dissected from a normally developing, self-pollinated ovule from one of the parents or a third species. The embryo and endosperm are transferred together to the surface of the culture medium (Williams et al., 1982). Modified versions of the nurse endosperm, such as embryo implantation or transplantation, have been adapted to other species (Williams, 1980; Williams and De Lautour, 1980). By using embryo rescue, one can achieve a $30 \%$ to $40 \%$ success rate with intergeneric crosses compared to a $1 \%$ success rate when embryonurse endosperm transplants are not used.

Small or young embryos that abort at early stages of development are often difficult to isolate. The nutritional requirements of young embryos vary greatly and the chances of damaging the embryos are great. In such situations, it may be possible to rescue embryos by ovary or ovule culture methods (Rangan, 1984). Ovaries are excised after pollination and the calyx, corolla, and stamens are removed. The ovary is surface-sterilized and cultured with the cut end of the pedicel inserted into the nutrient medium. If all goes well, the ovary then develops into a fruit with fully developed seeds. For ovule culture, the sterilized ovary is opened and the fertilized ovules are scooped out and transferred to the surface of the culture medium. The reasons for the successful recovery of hybrids from ovary or ovule culture rather than through embryo culture are probably related to nutritional and physical factors and protection of the embryo by the maternal or sporophytic tissues.

Light and temperature are two environmental factors that are of major concern in embryo culture. Embryos sometimes grow best when maintained in darkness for the first 1 to 2 weeks of culture and then transferred to light to allow chlorophyll formation. Isolated embryos frequently germinate in a wider temperature range than intact seeds. The optimum temperature depends on plant species, but normally a high range of 25 to 30C is used (Narayanaswamy and Norstog, 1964). Some embryos, from species such as Lilium, require a lower temperature, i.e., $17 \mathrm{C}$, and others require a cold treatment of $4 \mathrm{C}$ to break dormancy (Pierik, 1987).

The growth conditions of the mother plant are also a consideration in embryo culture. The endosperm and the cotyledons will develop more if the mother plant is grown under well-controlled conditions; embryo growth will consequently be promoted.

\section{MEDIA}

Dieterich (1924) showed that mature embryos could grow normally on a semisolid medium containing only Knop's mineral salts and $2.5 \%$ to $5 \%$ sucrose. However, many scientists believe that the most important aspect of embryo culture is medium selection. Several formulations of mineral salts have been used for embryo culture without much critical evaluation of the role of individual elements (Bhojwani and Razdan, 1983). Murashige and Skoog (1962) and Gamborg's B5 medium (Gamborg et al., 1968), with certain degrees of modification, are the most widely used basal media in embryo culture.

The exact nutritional requirement depends on the stage of embryo development. Raghavan (1966) identified two phases of embryo development. In the heterotrophic phase, the young embryo depends on the endosperm and the surrounding maternal tissues, and requires a more complex medium and higher osmotic pressure than older embryos. The continued development of young embryos requires complex media supplemented with combinations of vitamins, amino acids, growth hormones, and, in some cases, natural extracts, such as tomato juice and coconut milk, to support development.

During the autotrophic phase, the second stage of embryo growth, the embryo is metabolically capable of synthesizing substances required for its growth from the salts and sugar. In this phase, embryos can germinate and grow on a simple inorganic medium supplemented with a carbon source, such as sucrose.

Ammonium nitrate and potassium nitrate are the most frequently used sources of inorganic $\mathrm{N}$ in embryo culture. Ammonium in the medium is essential or preferential for proper growth and differentiation of immature embryos (Matsubara, 1964; Umbeck and Norstog, 1979). Ammonium usually is combined with an organic acid, particularly with malate or citrate anions. Among various amino acids, glutamine and asparagine are the most effective (Sanders and Burkholder, 1948). Casein hydrolysate is a complex mixture of amino acids and is commonly used in embryo culture media to stimulate growth. Vitamins, such as biotin, thiamine, pantothenic acid, nicotinic 
acid, ascorbic acid, inositol, and pyroxidine, are commonly added, but have not been proven to be essential.

Adding amino acids to the culture medium may stimulate embryo growth (Bhojwani and Razdan, 1983). Glutamine is the most effective amino acid for cultured embryo growth (Monnier, 1978). Asparagine may also enhance embryo growth (Hannig, 1904), but it can be inhibitory (Matsubara, 1964). Casein hydrolysate is a complex mixture of 18 amino acids that has been widely used as an additive to embryo culture media. When added alone to a medium, none of the amino acids match the beneficial effect of casein hydrolysate (Sanders and Burkholder, 1948). However, work with the induction and maturation of somatic embryos demonstrates that amino acids such as proline, serine, and glutamine can replace casein hydrolysate.

The landmark work of van Overbeek et al. (1942) demonstrated that embryos younger than the post-torpedo stage could be cultured by adding the liquid endosperm of coconut to the culture medium. By modifying a medium to mimic the endosperm that surrounds immature embryos in the ovule, success was obtained where it had not been possible previously. The growth-promoting factor in the coconut milk was referred to as "embryo factor." By using coconut milk in media for young embryos, precocious germination can be avoided. Other natural substances, such as skim milk, dried brewer's yeast (malt extract), casein hydrolysate, and diffusates from the seeds of several plant species, can substitute for coconut milk, depending on the species under investigation (Bhojwani and Razdan, 1983). Although synthetic media are used, these natural plant extracts are still suitable amino acid sources for culturing immature embryos. A purely synthetic medium can be developed to substitute for coconut milk by enriching White's (1934) medium with phosphate and fortifying with glutamine, alanine, and five other amino acids (Cameron-Mills and Duffus, 1977).

Sucrose is the most commonly used C energy source for embryo culture. Sucrose is primarily an energy source, although it also plays an important role in maintaining suitable osmotic potential of nutrient media. Mature embryos are usually grown on media with $2 \%$ to $3 \%$ sucrose, whereas immature embryos grow better at $8 \%$ to $12 \%$, which mimic the high osmotic potential within the young embryo sac. Generally, the younger the excised embryo, the higher the medium osmolarity required. Raghavan $(1977,1980)$ believes that this high osmolarity prevents precocious germination and keeps cells that are in a state of division from going into a state of elongation.

Agar is the most commonly used agent to solidify culture media. Concentrations of $0.5 \%$ to $1.5 \%$ are generally used for embryo culture (Hu and Wang, 1986). High concentrations of agar may inhibit growth due to reduced water availability, quality of agar, or contaminating salts.

Plant growth regulators generally play a small role in embryo culture. Exogenous auxins do not seem to be required for plant embryo growth in vitro (Norstog, 1979). This observation supports reports that somatic embryo induction is inhibited by high concentrations of exogenous auxin in the medium and stimulated by low concentrations or in its absence. Cytokinins, when used as the sole hormone, are ineffective or only slightly promote young embryo growth. However, they promote growth and differentiation of embryos when they are combined with some auxins (Veen, 1963). Monnier (1978) suggests that hormones should not be added to embryo culture media as they cause structural abnormalities. Auxins and cytokinins are not generally used for embryo culture unless callus induction is needed. Gibberellins sometimes stimulate precocious germination or are used to overcome dormancy.

\section{CONCLUSION}

Embryo culture is a valuable in vitro tool for breeding. It is most often used to rescue embryos from interspecific and intergeneric crosses and from embryos that do not fully develop naturally (as in early ripening and seedless fruit where the embryo aborts). The method also can be used to rescue seedless triploid embryos, produce haploids, overcome seed dormancy, or determine seed viability. It is useful in understanding embryo morphogenesis and precocious germination. As research continues with this technique, new and valuable uses will be developed to assist the biotechnological breeding of plants.

\section{Literature Cited}

Bhojwani, S.S. and M.K. Razdan. 1983. Plant tissue culture: Theory and practice. Elsevier, Amsterdam.

Cameron-Mills, V. and C.M. Duffus. 1977. The in vitro culture of immature barley embryos on different culture media. Ann. Bot. 41:1117-1127.

Collins, G.B. and J.W. Grosser. 1984. Culture of embryos, p. 241-257. In: I.K. Vasil (ed.). Cell culture and somatic cell genetics of plants. vol. 1. Laboratory procedures and their applications. Academic, New York.

Dietrich, K. 1924. Über Kultur von Embryonen ausserhalb des Samens. Flora (Jena) 117:379-417.

Dunwell, J.M. 1986. Pollen, ovule and embryo culture as tools in plant breeding, p. 375-404. In: L.A. Withers and P.G. Alderson (eds.). Plant tissue culture and its agricultural applications. Butterworths, London.

Gamborg, O.L., R.A. Miller, and K. Ojima. 1968. Nutrient requirements of suspension cultures of soybean root cells. Expt. Cell Res. 50:151-158.

Grout, B.W.W. 1986. Embryo culture and cryopreservation for the conservation of genetic resources of species with recalcitrant seed, p. 303-309. In: L.A. Withers and P.G. Alderson (eds.). Plant tissue culture and its agricultural applications. Butterworths, London.

Hannig, E. 1904. Zur Physiologie pflanzlicher Embryonen. I. Über die Kultur von Cruciferen-embryonen ausserhalb des Embryosacks. Bot. Ztg. 62:4580.

Hu, C. and P. Wang. 1986. Embryo culture: Technique and applications, p. $43-$ 96. In: D.A. Evans, W.R. Sharp, and P.V. Ammirato (eds.). Handbook of plant cell culture. vol. 4. Macmillan, New York.

Laibach, F. 1925. Das Taubwerden von Bastardsamen und die künstliche Aufzucht früh absterbender Bastardembryonen. Z. Bot. 17:417-459.

Matsubara, S. 1964. Effect of nitrogen compounds on the growth of isolated young embryos of Datura. Bot. Mag. (Tokyo) 77:253-259.

Monnier, M. 1978. Culture of zygotic embryos, p. 277-286. In: T.A. Thorpe (ed.). Frontiers of plant tissue culture 1978. Univ. of Calgary Press, Canada.

Murashige, T. and F. Skoog. 1962. A revised medium for rapid growth and bioassays with tobacco tissue cultures. Physiol. Plant. 15:473-497.

Narayanaswamy, S. and K. Norstog. 1964. Plant embryo culture. Bot. Rev. 30:587-628.

Norstog, K. 1979. Embryo culture as a tool in the study of comparative and developmental morphology, p. 179-202. In: W.R. Sharp, P.O. Larsen, E.F. Paddock, and V. Raghavan (eds.). Plant cell and tissue culture. Ohio State Univ. Press, Columbus.

Pierik, R.L.M. 1987. In vitro culture of higher plants. Martinus Nijhoff, Dordrecht, Netherlands.

Raghavan, V. 1966. Nutrition, growth and morphogenesis of plant embryos. Biol. Rev. 41:1-58.

Raghavan, V. 1977. Applied aspects of embryo culture, p. 375-397. In: J. Reinert and Y.P.S. Bajaj (eds.). Applied and fundamental aspects of plant cell, tissue, and organ culture. Springer-Verlag, Berlin.

Raghavan, V. 1980. Embryo culture, p. 209-240. In: I.K. Vasil (ed.). Perspectives in plant cell and tissue culture. Intl. Rev. Cytol., Suppl. 11B. Academic, New York.

Raghavan, V. 1986. Embryogenesis in angiosperms. Cambridge Univ. Press, Cambridge, U.K.

Ramming, D.W. 1985. In ovulo embryo culture of early-maturing Prunus. HortScience 20:419-420.

Ramming, D.W. 1990. The use of embryo culture in fruit breeding. HortScience 25:393-398.

Rangan, T.S. 1984. Culture of ovules, p. 227-231. In: I.K. Vasil (ed.). Cell culture and somatic cell genetics of plants. vol. 1. Laboratory procedures and their applications. Academic, New York.

Sanders, M.E. and P.R. Burkholder. 1948. Influence of amino acids on growth of Datura embryos in culture. Proc. Natl. Acad. Sci. USA 34:516526.

Sharma, H.C. and B.S. Gill. 1983. New hybrids between Agropyron and wheat. 2. Production, morphology and cytogenetic analysis of $F_{1}$ hybrids and backcross derivatives. Theor. Appl. Genet. 66:111-121.

Tukey, H.B. 1944. Excised-embryo method of testing the germinability of fruit seed with particular reference to peach seed. Proc. Amer. Soc. Hort. Sci. 45:211-219.

Umbeck, P.F. and K. Norstog. 1979. Effects of abscisic acid and ammonium ion on morphogenesis of cultured barley embryos. Bul. Torrey Bot. Club 106:110-116.

van Overbeek, J., M.E. Conklin, and A.F. Blakeslee. 1941. Factors in coconut milk essential for growth and development of very young Datura embryos. Science 94:350-351. 


\section{WORKSHOP}

van Overbeek, J., M.E. Conklin, and A.F. Blakeslee. 1942. Cultivation in vitro of small Datura embryos. Amer. J. Bot. 29:472-477.

Veen, H. 1963. The effect of various growth-regulators on embryos of Capsella bursapastoris growing in vitro. Acta Bot. Neerl. 12:129-171.

White, P.R. 1934. Potentially unlimited growth of excised tomato root tips in a liquid medium. Plant Physiol. 9:585-600.

Williams, E. 1980. Hybrids between Trifolium ambiguum and T. hybridum obtained with the aid of embryo culture. N.Z. J. Bot. 18:215-220.

Williams, E. and G. De Lautour. 1980. The use of embryo culture with transplanted nurse endosperm for the production of interspecific hybrids in pasture legumes. Bot. Gaz. (Chicago) 141:252-257.

Williams, E.G., I.M. Verry, and W.M. Williams. 1982. Use of embryo culture in interspecific hybridization, p. 119-128. In: I.K. Vasil, W.R. Scowcroft, and K.J. Frey (eds.). Plant improvement and somatic cell genetics. Academic, New York.

Yeung, E.C., T.A. Thorpe, and C.J. Jensen. 1981. In vitro fertilization and embryo culture, p. 253-271. In: T.A. Thorpe (ed.). Plant tissue culture: Methods and applications in agriculture. Academic, New York. 